\title{
Robot-assisted radical cystectomy: state of art and future perspectives
}

Cite this article: Mastroianni R, Simone G: Robot-assisted radical cystectomy: state of art and future perspectives. Ann Urol Oncol 2019; 2(2): 1-7. https://doi. org/10.32948/auo.2019.12.15

\author{
Riccardo Mastroianni $^{1,2}$, Giuseppe Simone ${ }^{1}$
}

\begin{abstract}
Bladder cancer $(\mathrm{BC})$ remains one of the most common cancer worldwide. Radical cystectomy (RC) and pelvic lymph node dissection (PLND) with urinary diversion (UD) is still considered the gold standard treatment for non-metastatic muscle invasive bladder cancer (MIBC) and for recurrent non-muscle invasive disease. The open approach remains the reference option of treatment for RC, even if robotic surgery is rapidly increasing. Nowadays, several studies have reported perioperative, functional and oncological outcomes of robotassisted radical cystectomy (RARC), but data are still immature to compare both procedures. All the current randomized controlled trials (RCTs), did not prove any significant difference between open RC and RARC, underlining no superiority between both procedures. Therefore, RARC is still considered an investigational procedure. On the other hand, modern robotic surgical practice has been evolved by the introduction of innovative technologies. The technological progress is improving, in particular in robotic surgery, offering several future perspectives, such as the ICG technique. The aim of the review is to describe the state of art, and to outline future perspectives of RARC, in order to establish the role of robotic surgery in the complex field of radical cystectomy.
\end{abstract}

Key words bladder cancer, radical cystectomy, robot-assisted radical cystectomy, urinary diversion, robotic surgery

1. Department of Urology, "Regina Elena” National Cancer Institute of Rome, Italy.

2. Department of Urology, "Sapienza" University of Rome, Italy.

Correspondence: Riccardo Mastroianni (Department of Urology, Viale dell’Università, 33, 00185, Rome (RM), Italy; Email: ric.mastroianni@libero.it). 


\section{Introduction}

Bladder cancer $(\mathrm{BC})$ remains one of the most common cancer worldwide. $\mathrm{BC}$ is the 7 th most commonly diagnosed cancer in males, and the 11th when both genders are considered. In the European Union, the age-standardised incidence rate is 19.1 for men, and 4.0 for women [1]. In Italy, in 2017 it has reported 27,000 new diagnosis of $\mathrm{BC}$ ( 21,700 for men and 5,300 for women), in particular at diagnosis $70 \%$ of patients has a non-invasive $\mathrm{BC}$ while $30 \%$ of patients has a muscle-invasive disease [2].

Radical cystectomy (RC) and pelvic lymph node dissection (PLND) with urinary diversion (UD) still remains the gold standard treatment for non-metastatic muscle invasive bladder cancer (MIBC) and for recurrent non-muscle invasive disease [1]. Actually, it is growing the literature about multimodality treatment (MMT) or trimodality treatment combines TURB, chemotherapy and radiation. The evidences supporting a bladdersparing approach to treat $\mathrm{BC}$ are few, and the impact of MMT, as compared to $\mathrm{RC}$, on long-term overall survival (OS) remains undefined. As a result, MMT could be offered as an alternative in highly selected patient population, especially for whom cystectomy is not an option $[1,3,4]$. Therefore, many patients continue to be offered radical surgery as the standard-of-care treatment.

\section{Open Radical Cystectomy vs Robot-assisted Radical Cystectomy: state of art}

The open approach is still considered the reference option of treatment for RC, even if the widespread use of robotic surgery is progressively changing this statement. However, data are immature to compare both approaches, therefore robot-assisted laparoscopic radical cystectomy (RARC) is still considered an investigational procedure. Several studies have reported that robotic approach reduces blood loss and transfusions, and it has a shorter length of hospital stay compared to open radical cystectomy (ORC) $[5,6]$. Despite these evidences, all the current randomized controlled trials (RCTs), including intermediate and long-term oncologic and functional outcomes, did not prove any significant difference (Table 1 - 2, Figure 1 - 2) [7-12].

Simone et al. [5] reported a propensity scored (PS) match analysis, to compare perioperative and mid-term oncologic outcomes of RARC with totally intracorporeal neobladder with open cohort, from a single center series. The open cohort experienced a higher incidence of perioperative complications $(91.3 \%$ vs $42.2 \%, p<0.001)$, most of which represented by the need for blood transfusion (Clavien grade II: $63 \%$ vs $9.4 \%$ for ORC and RARC, respectively). Consequently, low-grade complications were significantly more frequent in patients treated with ORC
(89.1\% vs $35.9 \%, p<0.001)$, while comparable incidences of highgrade complications were observed in both groups $(2.2 \%$ vs $6.3 \%$, respectively, $\mathrm{p}<0.311)$. Regarding oncologic outcomes, Simone et al. confirmed that RARC and ORC displayed comparable DFS (2yr: 87.8 vs 84.4 , 3-yr: 79.3 vs 84.4 , 4-yr: 79.3 vs 73.4 , respectively; $\log$ rank p < 0.746), CSS (2-yr: 89.6 vs 88.3 , 3-yr: 86.4 vs $85.3,4-$ yr: 86.4 vs 85.3 , respectively; $\log$ rank $\mathrm{p}<0.753)$ and OS rates $(2-$ yr: 85.2 vs 86,3 -yr: 82.1 vs 83 , 4- yr: 82.1 vs 79.6 , respectively; $\log$ rank $\mathrm{p}<0.909$ ). Collins et al. described comparable long-term oncologic outcomes, OS and CSS were at $3-\mathrm{yr} 78.5 \%$ and $80.4 \%$ and at 5-yr 68\% and 69.6\%, respectively [13].

There is a large consensus regarding the staging role of PLND during $\mathrm{RC}$, even if its therapeutic role and standard template have yet to be defined [1]. Standard PLND (s-PLND) involves removal of nodal tissue cranially up to the common iliac bifurcation, with the ureter being the medial border, and including the internal iliac, presacral, obturator fossa and external iliac nodes. Extended PLND (e-PLND) includes all lymph nodes in the region of aortic bifurcation, and presacral and common iliac vessels medial to the crossing ureters. The lateral borders are the genitofemoral nerves, caudally the circumflex iliac vein, the lacunar ligament and lymph node of Cloquet (Figure 3) [14]. Regarding the therapeutic role of PLND Bruins H.M. et al. [15], in a Systematic Review (SR), underlined that all fives studies comparing LND vs no LND reported a better oncologic outcome for the LND group. Regarding the template of LND it has reported a beneficial outcome for e-PLND in comparison with limited or s-PLND. In accord to the SR, Simone G. et al. [14] supported that e-PLND has both staging and therapeutic role. In fact, they reported that e-PLND was significantly associated with higher DFS (HR 1.96, P $<0.001$ ) and CSS (HR 1.76, P < 0.001) probabilities. Specifically, 1-year, 3-year and 5-year DFS estimates were $71.2 \%, 49.4 \%$ and $42.6 \%$ in patients receiving s-PLND, and $86 \%, 68.6 \%$ and $63.1 \%$ in patients receiving e-PLND, respectively (log-rank $\mathrm{P}<0.001$ ). Similarly, 1-year, 3-year and 5-year CSS estimates were $87.7 \%$, $62 \%$ and $50.9 \%$ in patients receiving s-PLND, and $93.5 \%, 78,5 \%$ and $68.8 \%$ in patients receiving e-PLND, respectively (log-rank P $<0.001)$. Moreover, it has reported that, at univariable analysis, the number of nodes removed (LN-c) was predictive of DFS (log-rank $\mathrm{P}=0.003)$ and CSS (log-rank $\mathrm{P}=0.018)$, but it failed to achieve statistical significance in multivariable analysis; this data would support the importance of defining the anatomical template of PLND. Therfore, LN-c is not an independent outcome predictor, but a surrogate of PLND extent and, somehow, a confounding variable.

Moreover, comparing RARC and ORC in the setting PLND, Simone G. et al. [5] did not show any statistically significant difference in terms of LN-c; reporting in the whole cohort, a

Table 1. Perioperative outcomes of RARC.

\begin{tabular}{|c|c|c|c|c|c|c|c|c|}
\hline Author & Year & $\begin{array}{l}\text { Patients } \\
\text { (n) }\end{array}$ & EBL (ml) & $\begin{array}{l}\text { LS } \\
\text { (days) } \\
\end{array}$ & $\begin{array}{l}\text { LG complica- } \\
\text { tions }(\%)\end{array}$ & $\begin{array}{l}\text { HG complica- } \\
\text { tions }(\%)\end{array}$ & $\begin{array}{l}\text { Intracorpore- } \\
\text { al UD }(\%)\end{array}$ & $\begin{array}{l}\text { Extracorpore- } \\
\text { al UD (\%) }\end{array}$ \\
\hline $\begin{array}{l}\text { Simone et al } \\
{[5,23]}\end{array}$ & 2018 & 64 & 210 & 8 & 36 & 6 & 100 & 0 \\
\hline Khan et al [7] & 2016 & 20 & 585 & 11.9 & 25 & 30 & 0 & 100 \\
\hline $\begin{array}{l}\text { Bochner et al } \\
\text { [8] }\end{array}$ & 2015 & 60 & 516 & 8 & 62 & 22 & 0 & 100 \\
\hline Nix et al [10] & 2009 & 21 & 258 & 5.1 & 29 & 6 & 0 & 100 \\
\hline $\begin{array}{l}\text { Parekh et al } \\
{[11]}\end{array}$ & 2018 & 150 & 300 & 6 & 78 & 22 & 0 & 100 \\
\hline $\begin{array}{l}\text { Gandaglia et } \\
\text { al [12] }\end{array}$ & 2016 & 138 & 300 & 13 & 44 & 16 & 31 & 69 \\
\hline
\end{tabular}



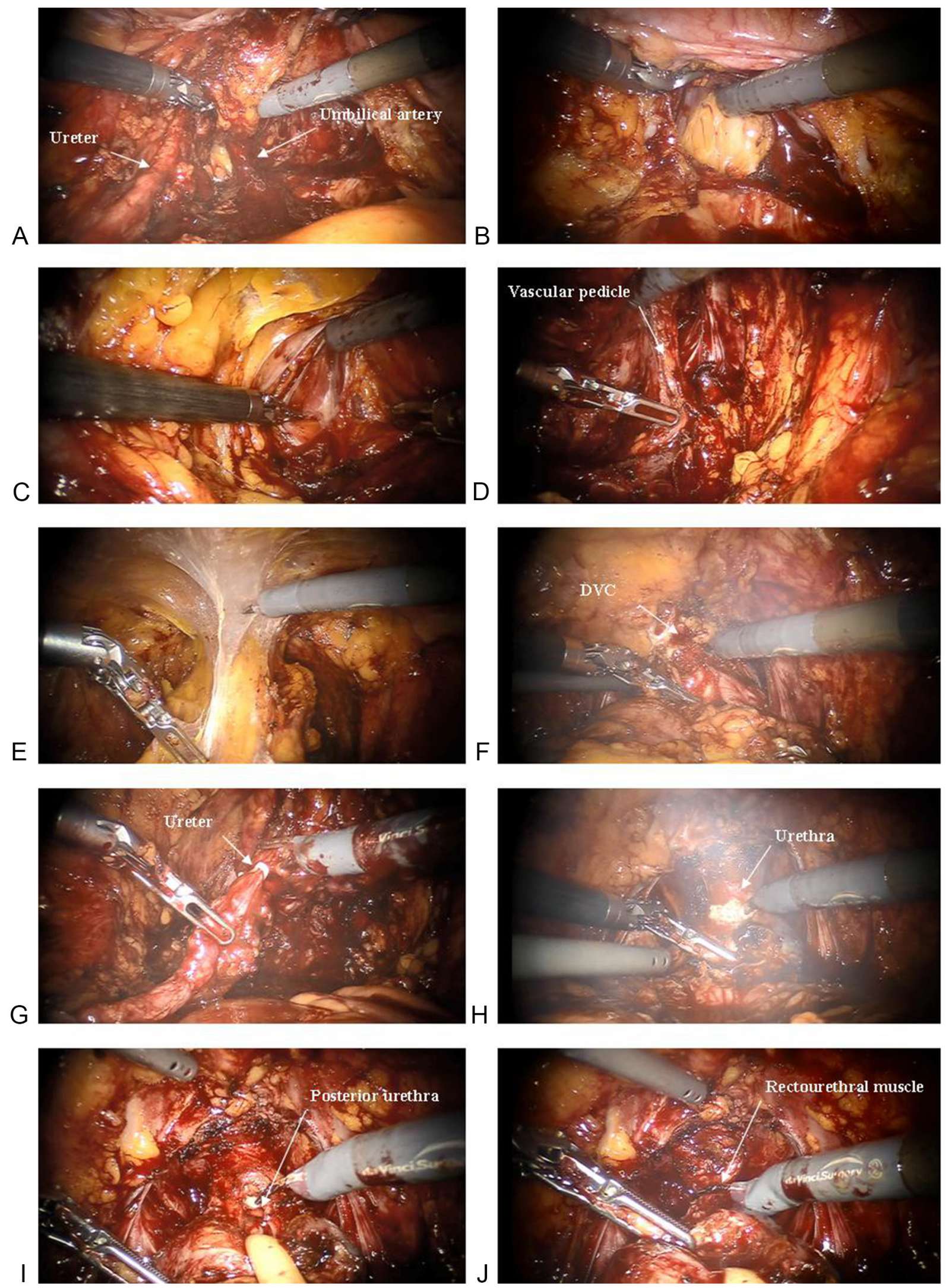

Figure 1. A: Isolation of ureter and umbilical artery; B: Incision of Douglas above the seminal vesicles; C: Opening of endopelvic fascia; D: Identification of vascular pedicle; E: Developing the space of Retzius; F: Section of dorsal vein complex (DVC); G: Clip ligation and section of ureter; H: Urethra incision; I: section of posterior urethra; J: section of Rectourethral muscle 

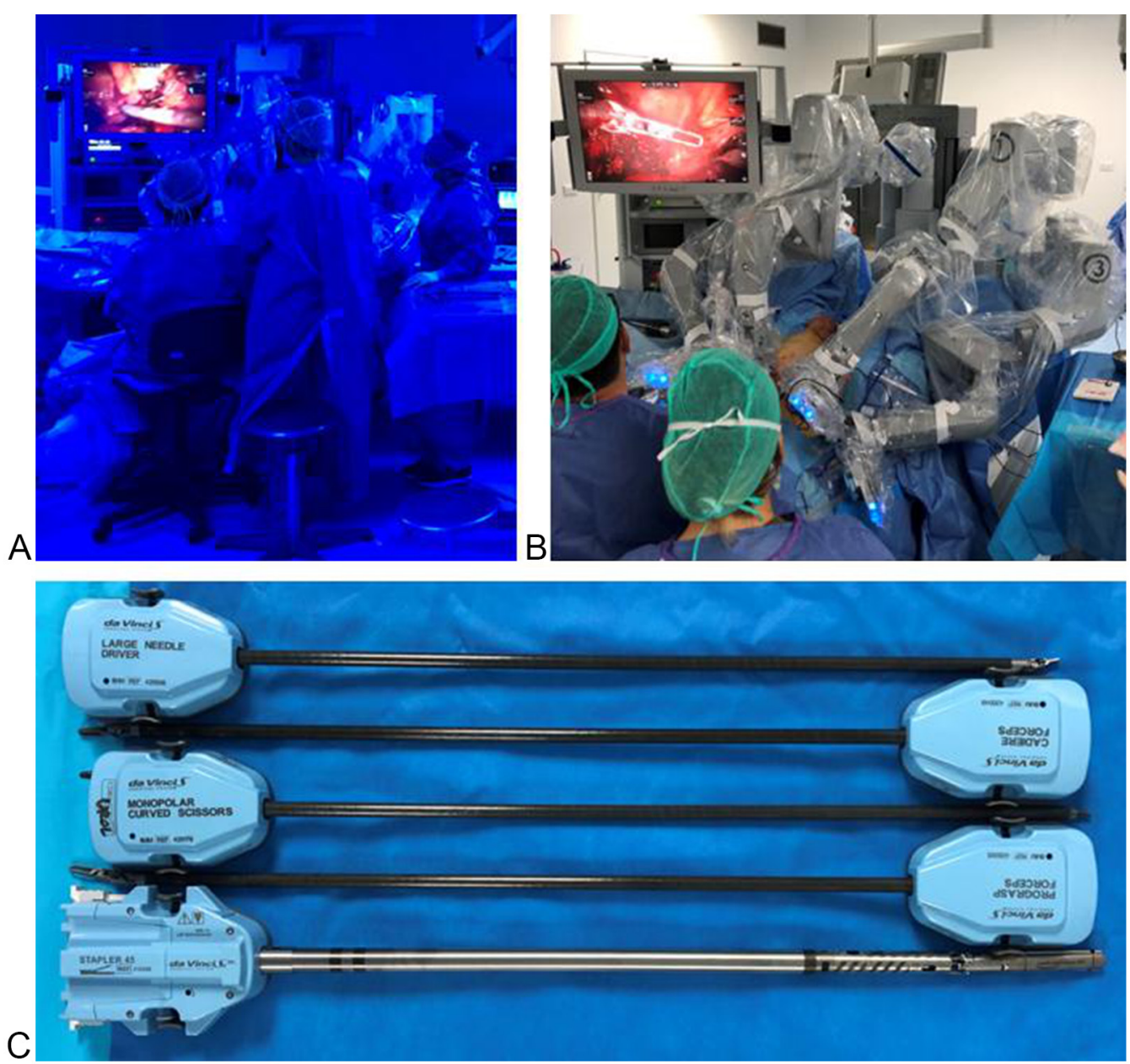

Figure 2. A - B: Operative room setting; C: robotic surgical equipment.

mean LN-c of $33.4( \pm 12.3)$ and $30.7( \pm 14.1)$ for robotic and open approach $(\mathrm{P}=0.16)$, respectively.

\section{Intracorporeal vs extracorporeal Robot-assisted Urinary Diversion}

The creation of urinary diversion is considered the most challenging step after RARC [16]. Therefore, despite it is growing the use of RARC, the majority of the centres still feel more confident performing an extracorporeal (ECUD) instead of a totally intracorporeal (ICUD) urinary diversion. Actually, underutilization of the intracorporeal approach might jeopardize an accurate interpretation of the results of current studies [6]. Indeed, data from the International Robotic Cystectomy Consortium (IRCC) showed that ICUD is performed in $72 \%$ of cases, whereas the ileal orthotopic neobladder only in $27 \%$, of which $82 \%$ utilize the extracorporeal approach [17]. Initially confined to high-volume centers, ICUD after RARC is also becoming popular since it provides quicker recovery of bowel function, shorter hospital stay and earlier return to daily life activities. Different types of ICUD

Table 2. Oncologic outcomes of RARC.

\begin{tabular}{|c|c|c|c|c|c|c|c|}
\hline Author & Year & Patients (n) & $\operatorname{PSM}(\%)$ & LNc (mean) & DFS & CSS & OS \\
\hline $\begin{array}{l}\text { Simone et al } \\
{[5,23]}\end{array}$ & 2018 & 64 & 0 & 33.4 & $87.8^{1}$ & $89.6^{1}$ & $85.2^{1}$ \\
\hline Khan et al [7] & 2016 & 20 & 15 & 16.3 & $73.7^{2}$ & $100^{2}$ & $95^{2}$ \\
\hline $\begin{array}{l}\text { Bochner et al } \\
{[8]}\end{array}$ & 2015 & 60 & 3.6 & 31.9 & NA & NA & NA \\
\hline Nix et al [10] & 2009 & 21 & 0 & 19 & NA & NA & NA \\
\hline $\begin{array}{l}\text { Parekh et al } \\
{[11]}\end{array}$ & 2018 & 150 & 6 & 23.3 & $72.3^{1}$ & $81.3^{1}$ & $93.3^{1}$ \\
\hline $\begin{array}{l}\text { Gandaglia et } \\
\text { al [12] }\end{array}$ & 2016 & 138 & 8.7 & 12 & $54.2^{3}$ & $73.5^{3}$ & $59.2^{3}$ \\
\hline
\end{tabular}

PSM: positive surgical margins; LNc: lymph node count; DFS: disease free survival; CSS: cancer specific survival; OS: overall survival. ${ }^{1} 2$-yr follow-up; ${ }^{2} 1$-yr follow-up; ${ }^{3} 5$-yr follow-up; NA: not available 

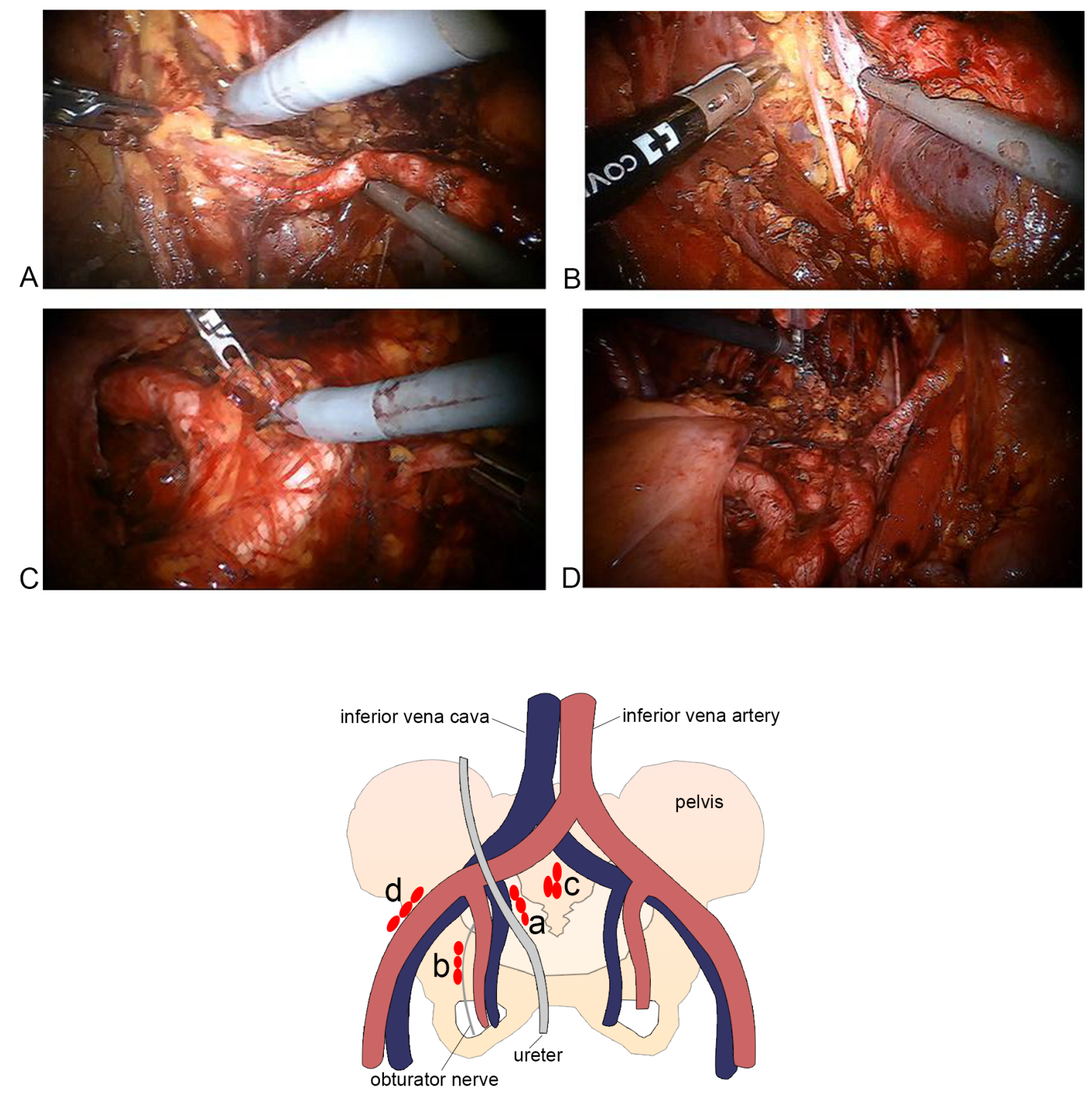

$\mathrm{E}$

Figure 3. Extended Pelvic Lymph Node Dissection (e-PLND). A: External iliac nodes; B: Obturator fossa; C: Presacral nodes; D: Final template; E: e-PLND template diagram: a) Common iliac nodes b) internal iliac nodes c) presacral nodes d) external iliac nodes.

have been reported such as: ileal conduit, orthotopic neobladder and continent cutaneous diversion. EAU guidelines underlines that although an intracorporeal neobladder is a more complex procedure, the choice of urinary diversion must not depend on the surgical approach [1].

Firstly, Intracorporeal ileal conduit is the most commonly performed, because of its simplicity, speed and safety execution with a low complication rate [18]. Secondly, orthotopic neobladder is still considered the most challenging ICUD, and several revisions of standard open reservoir configurations have been proposed to shorten the operative time of the robotic technique [1922]. Simone G. et al. [23] reported the technique for the completely intracorporeal Padua ileal bladder (PIB) configuration. They reported a $44.4 \%$ of perioperative complication rate, of which $17.8 \%$ of patients experienced a severe complication (Clavien grade $\geq 3)$. Moreover, a significant decrease $(\mathrm{P}<0.003)$ of mean operative time was observed in the last tertile, compared to the first one, and a trend towards significance was observed also for overall complications $(\mathrm{P}=0.065)$, high-grade complications $(\mathrm{P}=0.068)$ and duration of hospital stay $(\mathrm{P}=0.06)$. This underline the need of an high-volume center and a long learning curve to standardize the procedure, gaining the advantages of a minimally invasive approach. Regarding functional outcomes, 2-year day-time and night-time continence rates were $73.3 \%$ and $55.5 \%$, respectively. Finally, when patients are not candidates for orthotopic neobladder, a continent cutaneous diversion (CCD) should be a viable option. Desai M. et al. [24] showed their experience with intracorporeal Indiana pouch. They reported a median total operative time of 6 hours, including 3.5 hours for pouch reconstruction. It has reported a 40\% Clavien grade 1-2 complications rate, and a 30\% Clavien 3-5 complications rate. At a median follow-up of 13.7 months, all patients were completely continent. Clearly, we need more data 
with longer follow-up to assess the role of $\mathrm{CCD}$ as a valid option for UD, in particular to better evaluate long-term complications such as stone formation rate, around $10.8 \%$ in some large series, and stomal stenosis that is reported in $23.5 \%$ of patients [25].

\section{New technologies in robotic surgery: state of art and future perspectives}

Nowadays, RC is still considered a challenging procedure with high rate of complications. Hautmann R.E. et al. [26] in a large single-centre series described an early 90 -day complication rate of 58\%, at the same time, Novara G, et al. [27] reported a 3-month mortality rate of $3 \%$ and a complication rate of $49 \%$, of which $13 \%$ were grade 3 to 5 . Moreover, early morbidity of RC, in patients with recurrent non-muscle invasive disease, is comparable than in patients with MIBC [28], therefore surgical procedure is the key point to reduce overall complication rate.

Recently, we underline the importance to follow the technological progress in robotic surgery field, in order to outclass the ancient concept of "replicating the open principles" [29]. From the beginning of the robotic era up to day several studies reported comparable oncologic and functional outcomes between RARC and ORC, emphasizing no superiority between the two procedures. We are strongly convinced that this is the first step to establish the role of robotic surgery in the management of $\mathrm{BC}$, and now the technological revolution will guide robotic surgery to affirm its definitive role. It is growing the interest about the role of nearinfrared fluorescence technology that is able to augment anatomical structures identification. Manny TB et al. [30] described the feasibility of fluorescence-enhanced robotic radical cystectomy, using real-time cystoscope injection of indocyanine green (ICG), for tumor marking and identification of sentinel lymphatic drainage. It has reported a $90 \%$ of rate to identify sentinel nodal drainage, and in terms of ability to identify nodal metastasis, they found ICG lymphangiography to be highly sensitive. The different applications of ICG to evaluate bowel vascularity were first explored during RARC [19, 31, 32]. During intracorporeal robotic urinary diversion is more difficult to identify mesenteric arcades, therefore the ICG technique could be an easily way to maximize vascular preservation, avoiding gastrointestinal complications, that are considered the most common after RARC [33]. Moreover, the role of ICG technique to easily recognize tissue vascular perfusion was used to prevent ischemic ureteral complications, such as strictures. Ahmadi et al. [34] reported a significant reduction in the per-patient rate of uretero-enteric anastomotic stricture from 10 , $6 \%$ to $0 \%(\mathrm{p}=0.020)$.

\section{Conclusion}

In conclusion, even if RCTs failed to reveal a significant superiority of RARC compared to ORC [35], at the same time, it has to be considered that its non-inferiority is the start point to improve this investigational procedure. The current technological development, related to robotic surgery, is rapidly increasing, offering several future perspectives, that will definitely establish the role of robotic surgery in the complex field of radical cystectomy.

\section{Funding}

None.

\section{Ethics approval and consent to participate}

This study did not require prior ethics approval or consent from human participants.

\section{Author contributions}

RM: draft of manuscript, collation of information.

GS: revision, assistance with the above.

\section{Competing interests}

The authors declare no conflict of interest with the work.

\section{References}

1. Witjes JA, Bruins M, Cathomas R, Compérat E, Cowan NC, Gakis G, et al: EAU Guidelines on and Metastatic Bladder Cancer 2019; pii: S0302-2838(19)30763-8.

2. Antoni S, Ferlay J, Soerjomataram I, Znaor A, Jemal A, Bray F: Bladder Cancer Incidence and Mortality: A Global Overview and Recent Trends. Eur Urol 2017; 71(1): 96-108.

3. Efstathiou JA, Spiegel DY, Shipley WU, Heney NM, Kaufman DS, Niemierko A, et al: Long-term outcomes of selective bladder preservation by combined-modality therapy for invasive bladder cancer: The MGH experience. Eur Urol 2012; 61(4): 705-711.

4. Seisen T, Sun M, Lipsitz SR, Abdollah F, Leow JJ, Menon M, et al: Comparative Effectiveness of Trimodal Therapy Versus Radical Cystectomy for Localized Muscle-invasive Urothelial Carcinoma of the Bladder. Eur Urol 2017; 72(4): 483-487.

5. Simone G, Tuderti G, Misuraca L, Anceschi U, Ferriero M, Minisola F, et al: Perioperative and mid-term oncologic outcomes of robotic assisted radical cystectomy with totally intracorporeal neobladder: Results of a propensity score matched comparison with open cohort from a single-centre series. Eur J Surg Oncol 2018; 44(9): 1432-1438.

6. Tyritzis S, Collins J, Wiklund N: The current status of robot-assisted cystectomy. Indian J Urol 2018; 34(2): 101-109.

7. Khan MS, Gan C, Ahmed K, Ismail AF, Watkins J, Summers JA, et al: A single-centre early phase randomised controlled three-arm trial of open, Robotic, and Laparoscopic Radical Cystectomy (CORAL). Eur Urol 2016; 69(4): 613-621.

8. Bochner BH, Dalbagni G, Sjoberg DD, Silberstein J, Keren Paz GE, Donat SMH, et al: Comparing open radical cystectomy and robotassisted laparoscopic radical cystectomy: A randomized clinical trial. Eur Urol 2015; 67(6): 1042-1050.

9. Messer JC, Punnen S, Fitzgerald J, Svatek R, Parekh DJ: Healthrelated quality of life from a prospective randomised clinical trial of robot-assisted laparoscopic vs open radical cystectomy. BJU Int 2014; 114(6): 896-902.

10. Nix J, Smith A, Kurpad R, Nielsen ME, Wallen EM, Pruthi RS: Prospective Randomized Controlled Trial of Robotic versus Open Radical Cystectomy for Bladder Cancer: Perioperative and Pathologic Results. Eur Urol 2010; 57(2): 196-201.

11. Parekh DJ, Reis IM, Castle EP, Gonzalgo ML, Woods ME, Svatek RS, et al: Robot-assisted radical cystectomy versus open radical cystectomy in patients with bladder cancer (RAZOR): an open-label, randomised, phase 3, non-inferiority trial. Lancet (London, England) 2018; 391(10139): 2525-2536.

12. Gandaglia G, Karl A, Novara G, de Groote R, Buchner A, D'Hondt F, et al: Perioperative and oncologic outcomes of robot-assisted vs. open radical cystectomy in bladder cancer patients: A comparison of two high-volume referral centers. Eur J Surg Oncol 2016; 42(11): 1736-1743.

13. Collins JW, Sooriakumaran P, Sanchez-Salas R, Ahonen R, Nyberg T, Wiklund NP, et al: Robot-assisted radical cystectomy with intracorporeal neobladder diversion: The karolinska experience. Indian J Urol 2014; 30(3): 307-313.

14. Simone G, Papalia R, Ferriero M, Guaglianone S, Castelli E, Collura D, et al: Stage-specific impact of extended versus standard pelvic lymph node dissection in radical cystectomy. Int J Urol 2013; 20(4): 
390-397.

15. Bruins HM, Veskimae E, Hernandez V, Imamura M, Neuberger MM, Dahm P, et al: The impact of the extent of lymphadenectomy on oncologic outcomes in patients undergoing radical cystectomy for bladder cancer: A systematic review. Eur Urol 2014; 66(6): 1065 1077.

16. Cacciamani GE, Rajarubendra N, Artibani W, Gill IS: Robotic intracorporeal urinary diversion: state of the art. Curr Opin Urol 2019; 29(3): 293-300

17. Ahmed K, Khan SA, Hayn MH, Agarwal PK, Badani KK, Derya Balbay M, et al: Analysis of intracorporeal compared with extracorporeal urinary diversion after robot-assisted radical cystectomy: Results from the international robotic cystectomy consortium. Eur Urol 2014; 65(2): 340-347.

18. Hussein AA, Elsayed AS, Aldhaam NA, Jing Z, Osei J, Kaouk J, et al: Comparison of Long-Term Oncologic Outcomes among Historical Open and Minimally Invasive Retrospective Studies. J Urol 2019: 101097JU0000000000000386.

19. Goh AC, Gill IS, Lee DJ, de Castro Abreu AL, Fairey AS, Leslie S, et al: Robotic intracorporeal orthotopic ileal neobladder: replicating open surgical principles. Eur Urol 2012; 62(5): 891-901.

20. Pruthi RS, Nix J, McRackan D, Hickerson A, Nielsen ME, Raynor $\mathrm{M}$, et al: Robotic-Assisted Laparoscopic Intracorporeal Urinary Diversion. Eur Urol 2010; 57(6): 1013-1021.

21. Wiklund NP, Poulakis V: Robotic neobladder. BJU Int 2011; 107(9): 1514-1537.

22. Jonsson MN, Adding LC, Hosseini A, Schumacher MC, Volz D, Nilsson A, et al: Robot-assisted radical cystectomy with intracorporeal urinary diversion in patients with transitional cell carcinoma of the bladder. Eur Urol 2011; 60(5): 1066-1073.

23. Simone G, Papalia R, Misuraca L, Tuderti G, Minisola F, Ferriero $\mathrm{M}$, et al: Robotic Intracorporeal Padua Ileal Bladder: Surgical Technique, Perioperative, Oncologic and Functional Outcomes. Eur Urol 2018; 73(6): 934-940.

24. Desai MM, Simone G, de Castro Abreu AL, Chopra S, Ferriero M, Guaglianone S, et al: Robotic Intracorporeal Continent Cutaneous Diversion. J Urol 2017; 198(2): 436-444.

25. Wiesner C, Bonfig R, Stein R, Gerharz EW, Pahernik S, Riedmiller $\mathrm{H}$, et al: Continent cutaneous urinary diversion: Long-term followup of more than 800 patients with ileocecal reservoirs. World J Urol 2006; 24(3): 315-318.

26. Hautmann RE, De Petriconi RC, Volkmer BG: Lessons learned from 1,000 neobladders: The 90-day complication rate. J Urol 2010; 184(3): 990-994.

27. Novara G, De Marco V, Aragona M, Boscolo-Berto R, Cavalleri S, Artibani W, et al: Complications and Mortality After Radical Cystectomy for Bladder Transitional Cell Cancer. J Urol 2009; 182(3): 914-921.

28. Cookson MS, Chang SS, Wells N, Parekh DJ, Smith JA: Complications of radical cystectomy for nonmuscle invasive disease: Comparison with muscle invasive disease. J Urol 2003; 169(1): 101104.

29. Brassetti A, Mastroianni R, Simone G: Are we really seeking for equivalence ? - The virtue of the robot is in technology. Trans Androl Urol 2019; 8(S5): 35-37.

30. Manny TB, Hemal AK: Fluorescence-enhanced Robotic Radical Cystectomy Using Unconjugated Indocyanine Green for Pelvic Lymphangiography, Tumor Marking, and Mesenteric Angiography: The Initial Clinical Experience. Urology 2014; 83(4): 824-829.

31. Jafari MD, Lee KH, Halabi WJ, Mills SD, Carmichael JC, Stamos MJ, et al: The use of indocyanine green fluorescence to assess anastomotic perfusion during robotic assisted laparoscopic rectal surgery. Surg Endosc 2013; 27(8): 3003-3008.

32. Ashitate Y, Vooght CS, Hutteman M, Oketokoun R, Choi HS, Frangioni J V: Simultaneous assessment of luminal integrity and vascular perfusion of the gastrointestinal tract using dual-channel near-infrared fluorescence. Mol Imaging 2012; 11(4): 301-308.

33. Johar RS, Hayn MH, Stegemann AP, Ahmed K, Agarwal P, Balbay $\mathrm{MD}$, et al: Complications after robot-assisted radical cystectomy: Results from the international robotic cystectomy consortium. Eur Urol 2013; 64(1): 52-57.

34. Ahmadi N, Ashrafi AN, Hartman N, Shakir A, Cacciamani GE, Freitas D, et al: Use of indocyanine green to minimise ureteroenteric strictures after robotic radical cystectomy. BJU Int 2019; 124(2): 302-307.

35. Rai BP, Bondad J, Vasdev N, Adshead J, Lane T, Ahmed K, et al: Robotic versus open radical cystectomy for bladder cancer in adults. Cochrane Database Syst Rev 2019; 4: CD011903. 